\title{
Uric Acid is Positively Associated with Metabolic Syndrome but Negatively Associated with Diabetes in Japanese Men
}

\author{
Eiji Oda ${ }^{1}$, Ryu Kawai ${ }^{1}$, Vijayakumar Sukumaran ${ }^{2}$ and Kenichi Watanabe ${ }^{2}$
}

\begin{abstract}
Background The relationships between uric acid and metabolic syndrome (MetS) and diabetes, as well as the gender differences in these relationships are controversial.

Methods Medical check-up data from 2,449 Japanese men and 1,448 Japanese women were examined. The prevalence of MetS and diabetes was calculated by the quartiles of serum levels of uric acid. Correlation coefficients between uric acid and MetS-related risk factors were calculated and compared between men and women.

Results The prevalence of MetS in the 3rd quartile (Q3) of uric acid was significantly higher than that in the 1st (lowest) quartile (Q1) and the prevalence of MetS in the 4th quartile (Q4) was significantly higher than that in Q1, the 2nd quartile $(\mathrm{Q} 2)$, and Q3 in men. The prevalence of MetS in Q4 was significantly higher than that in Q1, Q2, and Q3 in women. The prevalence of diabetes in Q3 was significantly lower than that in Q1 and the prevalence of diabetes in Q4 was significantly lower than that in Q1 and Q2 in men. The prevalence of diabetes was not significantly different among the quartiles of uric acid in women. The ageadjusted correlation coefficient between uric acid and fasting glucose was not significant in men.

Conclusion Uric acid is positively associated with metabolic syndrome but negatively associated with diabetes in Japanese men.
\end{abstract}

Key words: uric acid, metabolic syndrome, diabetes, gender difference

(Inter Med 48: 1785-1791, 2009)

(DOI: 10.2169/internalmedicine.48.2426)

\section{Introduction}

Uric acid is the final oxidation product of purine catabolism and increased serum concentrations of uric acid have been implicated in cardiovascular disease. Facchini et al demonstrated that urinary uric acid clearance decreases in proportion to the increase in insulin resistance leading to an increase in serum uric acid concentration (1). Thus, uric acid may be a component of insulin resistance syndrome or metabolic syndrome (MetS) (2-5). Various mechanisms have been suggested through which uric acid may be implicated in the atherosclerotic process and its clinical complications. However, the contribution of uric acid to atherosclerotic vascular disease is still controversial. Uric acid can act as a prooxidant, particularly at increased concentrations, and may thus be a marker of oxidative stress, but it may also have a therapeutic role as an antioxidant (6). Patterson et al, using a normal human serum ultrafiltrate, demonstrated that uric acid protects native low-density lipoprotein (LDL) against oxidation by transition metal ions, but it accelerates the oxidation of mildly oxidized LDL (7). Thus, although there are plausible mechanisms to suggest uric acid as a potential direct mediator of MetS, diabetes, and cardiovascular disease, the relationships between uric acid and diabetes and cardiovascular disease are controversial and there may be gender and ethnic differences in these relationships (8-14).

${ }^{1}$ Medical Check-up Center, Tachikawa Medical Center, Nagaoka and ${ }^{2}$ Laboratory of Clinical Pharmacology, Department of Pharmacy, Niigata University of Pharmacy and Applied Life Sciences, Niigata

Received for publication May 1, 2009; Accepted for publication July 3, 2009

Correspondence to Dr. Eiji Oda, ijie@ venus.sannet.ne.jp 


\section{Methods}

\section{Subjects}

Between April 1, 2008 and March 31, 2009, 2,541 men and 1,502 women visited our medical check-up center for "Ningen Dock", a program for general health screening recommended by Japan Society of "Ningen Dock" (general health screening). Visitors were all required to fill out a questionnaire prepared by the Ministry of Health, Labor, and Welfare for the purpose of "Special Health Examination and Instruction" including questions about history of stroke and ischemic heart disease, smoking and drinking status, and antihypertensive, hypoglycemic, and antihyperlipidemic medications. Among these persons 25 men and 20 women without signed consent, 12 men and 15 women lacking respiratory function data, 5 men and a woman lacking body fat percentage data, a man and a woman lacking renal function data, and 33 men and 12 women with high-sensitivity Creactive protein (hs-CRP) levels of higher than $10 \mathrm{mg} / \mathrm{L}$ were excluded from the subjects of the present study resulting in a total of 2,449 men and 1,448 women. The protocol for the present study was approved by the Ethics Committee at Tachikawa Medical Center and signed informed consent was obtained from each subject.

\section{Measurements}

After an overnight fast, blood samples were obtained to measure blood levels of routine medical check-up tests: glucose, triglycerides, high-density lipoprotein (HDL) cholesterol, LDL cholesterol, hemoglobin A1c, uric acid, blood cell counts, electrolytes, liver and kidney function tests, and hs-CRP. Simple qualitative urinalyses were performed with test papers. Chemical measurements were performed at BML Nagaoka (Nagaoka, Japan) with routine laboratory methods except for hs-CRP which was measured at BML General Laboratory (Tokyo, Japan) with nephelometry using N-latex CRP-2 (Siemens Healthcare Japan, Tokyo, Japan). The measurement limit of hs-CRP was $0.02 \mathrm{mg} / \mathrm{L}$ and the value of hs-CRP less than the measurement limit was considered as $0.01 \mathrm{mg} / \mathrm{L}$. Respiratory function tests were performed with Autospirometer System 7 (Minato Medical Science, Osaka, Japan). Estimated glomerular filtration rate (eGFR) was calculated as eGFR $\left(\mathrm{mL} / \mathrm{min} / 1.73 \mathrm{~m}^{2}\right)=194 \times$ creatinine $^{-1.094} \times$ age $^{-0.287}$ in men, and $194 \times$ creatinine $e^{-1.094} \times$ age $^{-0.287} \times 0.739$ in women according to the recommendation from the Japanese Society of Nephrology. Body fat percentage was measured with bioelectrical impedance analysis using TBF-210 (TANITA, Tokyo, Japan). An average systolic blood pressure (SBP) and diastolic blood pressure (DBP) was calculated from two measurements with the subjects in a sitting position after 5 minutes rest. Heart rate was automatically recorded with electrocardiography. Body weight was measured with the subjects wearing light clothes provided by our center and the weight of the clothes was sub- tracted from the measured body weight. Waist circumference was measured at the level of the umbilicus. Body mass index (BMI) was calculated as weight in kilograms divided by height squared in meters.

\section{Definitions}

We adopted the revised National Cholesterol Education Program (NCEP) definition (3) for MetS criteria because the Japanese definition of MetS (JMetS) (15) which includes obesity as an inevitable component was already revealed to be inappropriate by recent large longitudinal epidemiological studies (16-19). MetS was defined by NCEP criteria (3) as three or more of five components where the cut-off point of waist circumference was modified for Japanese as $\geq 90 \mathrm{~cm}$ in men and $\geq 80 \mathrm{~cm}$ in women according to the recommendation by International Diabetes Federation (4). The cut-off points of other components were SBP $\geq 130 \mathrm{mmHg}$ and/or DBP $\geq 85 \mathrm{mmHg}$ for blood pressure, $\geq 150 \mathrm{mg} / \mathrm{dL}$ for triglycerides, $<40 \mathrm{mg} / \mathrm{dL}$ in men and $<50 \mathrm{mg} / \mathrm{dL}$ in women for HDL cholesterol, and $\geq 100 \mathrm{mg} / \mathrm{dL}$ for fasting glucose. Subjects receiving antihypertensive or hypoglycemic medication were considered to have the respective component. JMetS defined by the Examination Committee for Criteria of Metabolic Syndrome (15) was also examined. The criteria of JMetS is waist circumference $\geq 85$ in men and $\geq 90$ in women plus 2 or more of the following 3 components; SBP $\geq 130 \mathrm{mmHg}$ and/or DBP $\geq 85 \mathrm{mmHg}$, triglycerides $\geq 150$ $\mathrm{mg} / \mathrm{dL}$ and/or HDL cholesterol $<40 \mathrm{mg} / \mathrm{dL}$, and fasting glucose $\geq 110 \mathrm{mg} / \mathrm{dL}$. Diabetes was defined as fasting glucose $\geq 126 \mathrm{mg} / \mathrm{dL}$ and/or hypoglycemic medication. Impaired fasting glucose (IFG) was defined as $100 \mathrm{mg} / \mathrm{dL} \leq$ fasting glucose $<126 \mathrm{mg} / \mathrm{dL}$. Chronic kidney disease (CKD) was defined as eGFR $<60 \mathrm{~mL} / \mathrm{min} / 1.73 \mathrm{~m}^{2}$ and/or proteinuria.

\section{Statistical analysis}

The prevalence of MetS, JMetS, IFG, and diabetes was compared among the quartiles of serum uric acid level by gender. Spearman's correlation coefficients and age-adjusted correlation coefficients between uric acid and other MetSrelated risk factors were calculated by gender. Spearman's correlation coefficients were recalculated excluding diabetic patients. Statistical analyses were performed using Dr SPSS2. Means were compared with 2-sided t-tests, ratios were compared with chi-square tests. $\mathrm{P}$ values of $<0.05$ were considered to be statistically significant except for ratios among the quartiles for which $\mathrm{p}$ values of $<0.008$ were considered to be statistically significant according to a Bonferroni's test.

\section{Results}

Basal data are shown in Table 1. The subjects were 2,449 Japanese men aged 51.9 \pm 9.6 (mean \pm SD) years and 1,448 Japanese women aged 51.5 \pm 9.8 years. BMI, waist circumference, SBP, DBP, fasting glucose, triglycerides, hs-CRP, gamma glutamyltransferase (GGT), alanine aminotransferase 
Table 1. Basal Data

\begin{tabular}{|c|c|c|c|}
\hline & $\begin{array}{c}\text { men } \\
\mathrm{n}=2449\end{array}$ & $\begin{array}{c}\text { women } \\
n=1448\end{array}$ & $\mathrm{p}$ \\
\hline age (year) & $51.9 \pm 9.6$ & $51.5 \pm 9.8$ & ns \\
\hline body mass index $\left(\mathrm{kg} / \mathrm{m}^{2}\right)$ & $23.2 \pm 3.0$ & $21.7 \pm 3.1$ & $<0.0001$ \\
\hline body fat percentage (\%) & $22.2 \pm 5.1$ & $26.8 \pm 5.9$ & $<0.0001$ \\
\hline waist circumference $(\mathrm{cm})$ & $84.3 \pm 8.1$ & $78.9 \pm 8.6$ & $<0.0001$ \\
\hline systolic blood pressure $(\mathrm{mmHg})$ & $122.0 \pm 17.4$ & $112.6 \pm 17.2$ & $<0.0001$ \\
\hline diastolic blood pressure $(\mathrm{mmHg})$ & $77.4 \pm 10.8$ & $70.4 \pm 10.4$ & $<0.0001$ \\
\hline fasting glucose (mg/dL) & $96.2 \pm 15.4$ & $89.7 \pm 11.2$ & $<0.0001$ \\
\hline triglycerides (mg/dL) & $122.6 \pm 81.3$ & $72(56,99)$ & $<0.0001$ \\
\hline HDL cholesterol (mg/dL) & $57.7 \pm 14.5$ & $67.1 \pm 14.7$ & $<0.0001$ \\
\hline high-sensitivity CRP (mg/L) & $0.31(0.17,0.64)$ & $0.22(0.11,0.47)$ & $<0.0001$ \\
\hline gamma glutamyltransferase (IU/L) & $36(24,58)$ & $18(14,25)$ & $<0.0001$ \\
\hline alanine aminotransferase (IU/L) & $26.9 \pm 18.6$ & $18.3 \pm 13.9$ & $<0.0001$ \\
\hline LDL cholesterol (mg/dL) & $121.0 \pm 29.7$ & $120.8 \pm 29.6$ & ns \\
\hline uric acid (mg/dL) & $6.1 \pm 1.3$ & $4.5 \pm 1.0$ & $<0.0001$ \\
\hline hemoglobin A1c (\%) & $5.1 \pm 0.5$ & $5.0 \pm 0.4$ & 0.0004 \\
\hline white blood cell count $\left(/ \mathrm{L}^{-6}\right)$ & $5574 \pm 1489$ & $4881 \pm 1295$ & $<0.0001$ \\
\hline eGFR $\left(\mathrm{mL} / \mathrm{min} / 1.73 \mathrm{~m}^{2}\right)$ & $78.2 \pm 12.8$ & $79.9 \pm 13.2$ & $<0.0001$ \\
\hline metabolic syndrome & 14.5 & 9.0 & $<0.0001$ \\
\hline Japanese metabolic syndrome & 13.4 & 3.0 & $<0.0001$ \\
\hline diabetes & 5.8 & 1.9 & $<0.0001$ \\
\hline chronic kidney disease & 8.8 & 7.6 & ns \\
\hline coronary heart disease & 4.2 & 1.6 & $<0.0001$ \\
\hline stroke & 1.7 & 1.1 & ns \\
\hline antihypertensive medication & 18.9 & 10.2 & $<0.0001$ \\
\hline hypoglycemic medication & 3.7 & 1.2 & $<0.0001$ \\
\hline antihyperlipidemic medication & 9.4 & 10.4 & ns \\
\hline current smoker & 34.0 & 7.9 & $<0.0001$ \\
\hline everyday drinker & 51.0 & 15.7 & $<0.0001$ \\
\hline
\end{tabular}

Data are presented as mean \pm SD, median (the 1 st quartile, the 3rd quartile), or $\%$.

(ALT), uric acid, hemoglobin A1c, and white blood cell count were significantly higher in men than in women and body fat percentage, HDL cholesterol, and eGFR were significantly lower in men than in women. LDL cholesterol was not significantly different between men and women. The prevalence of MetS, diabetes, and coronary heart disease was significantly higher in men but the prevalence of CKD and stroke was not significantly different between men and women. The prevalence of JMetS in women was very low. Table 2 shows the prevalence of MetS, JMetS, IFG, and diabetes by the quartiles of serum uric acid level and Fig. 1 illustrates the prevalence of MetS and diabetes by the quartiles of serum uric acid level. The prevalence of MetS in the 3rd quartile (Q3) was significantly higher than that in the 1st (lowest) quartile $(\mathrm{Q} 1)(\mathrm{p}<0.008)$ and the prevalence of MetS in the 4th quartile (Q4) was significantly higher than those in $\mathrm{Q} 1 \quad(\mathrm{p}<0.0001)$, the 2nd quartile (Q2) ( $<<$ $0.0001)$, and $\mathrm{Q} 3(\mathrm{p}<0.001)$ in men. The prevalence of MetS in the 4th quartile (Q4) was significantly higher than those in Q1 $(\mathrm{p}<0.0001), \mathrm{Q} 2(\mathrm{p}<0.0001)$, and Q3 $(\mathrm{p}<0.0001)$ in women. The differences in the prevalence of JMetS by the quartiles of uric acid were nearly similar to those of MetS.
The prevalence of IFG was higher in Q4 than in Q1 in men $(\mathrm{p}<0.008)$. The prevalence of IFG was higher in Q3 $(\mathrm{p}<$ $0.008)$ and in $\mathrm{Q} 4(\mathrm{p}<0.0001)$ than in $\mathrm{Q} 1$ in women. The prevalence of diabetes in Q3 was significantly lower than that in $\mathrm{Q} 1 \quad(\mathrm{p}<0.008)$ and the prevalence of diabetes in $\mathrm{Q} 4$ was significantly lower than those in Q1 $(\mathrm{p}<0.0001)$ and Q2 $(p<0.008)$ in men. The prevalence of diabetes was not significantly different among the quartiles of uric acid in women. Spearman's correlation coefficients between uric acid and MetS-related risk factors are shown in Table 3. The correlation coefficient between uric and fasting glucose and that between uric acid and hemoglobin A1c were not significant in men. Then, age-adjusted correlation coefficients between uric acid and MetS-related risk factors were calculated as shown in Table 4 because the correlation coefficient between uric acid and age was negative in men. The ageadjusted correlation coefficient between uric acid and body fat percentage and that between uric acid and fasting glucose were not significant in men and the age-adjusted correlation coefficient between uric acid and waist circumference was not significant in women. Table 5 presents Spearman's correlation coefficients between uric acid and MetS-related 
Table 2. Prevalence of MetS, JMetS, IFG, and Diabetes by the Quartiles of Uric Acid

\begin{tabular}{|c|c|c|c|c|c|}
\hline & quartiles & Q1 & Q2 & Q3 & Q4 \\
\hline \multirow{6}{*}{ men } & range of uric acid (mg/dL) & $1.0-5.2$ & $5.3-6.0$ & $6.1-6.8$ & $6.9-12.1$ \\
\hline & $\mathrm{n}$ & 614 & 568 & 632 & 635 \\
\hline & MetS (\%) & 9.3 & 10.4 & $15.2^{*}$ & $22.5^{* *}$ \\
\hline & JMetS (\%) & 9.9 & 9.7 & 12.0 & $21.3^{\#}$ \\
\hline & IFG (\%) & 18.2 & 19.7 & 21.4 & $25.6^{*}$ \\
\hline & diabetes (\%) & 9.1 & 6.5 & $5.2^{*}$ & $2.7^{\dagger}$ \\
\hline \multirow{6}{*}{ women } & range of uric acid (mg/dL) & $1.8-3.8$ & $3.9-4.4$ & $4.5-5.0$ & $5.1-9.5$ \\
\hline & $\mathrm{n}$ & 370 & 359 & 350 & 369 \\
\hline & MetS (\%) & 3.2 & 3.6 & 7.1 & $20.0^{\#}$ \\
\hline & JMetS (\%) & 0.8 & 1.4 & 2.0 & $7.6^{* *}$ \\
\hline & IFG (\%) & 4.6 & 8.6 & 9.4 & $18.7^{* *}$ \\
\hline & diabetes (\%) & 0.5 & 1.4 & 3.1 & 2.7 \\
\hline
\end{tabular}

MetS: metabolic syndrome, JMetS: Japanese metabolic syndrome, IFG: impaired fasting glucose. ${ }^{*} p<$ 0.008 compared with $\mathrm{Q} 1,{ }^{* *} \mathrm{p}<0.0001$ compared with $\mathrm{Q} 1$ or $\mathrm{Q} 2, \mathrm{p}<0.001$ compared with $\mathrm{Q} 3,{ }^{*} \mathrm{p}<0.0001$ compared with $\mathrm{Q} 1, \mathrm{Q} 2$, or $\mathrm{Q} 3{ }^{\dagger} \mathrm{p}<0.0001$ compared with $\mathrm{Q} 1, \mathrm{p}<0.008$ compared with $\mathrm{Q} 2$.

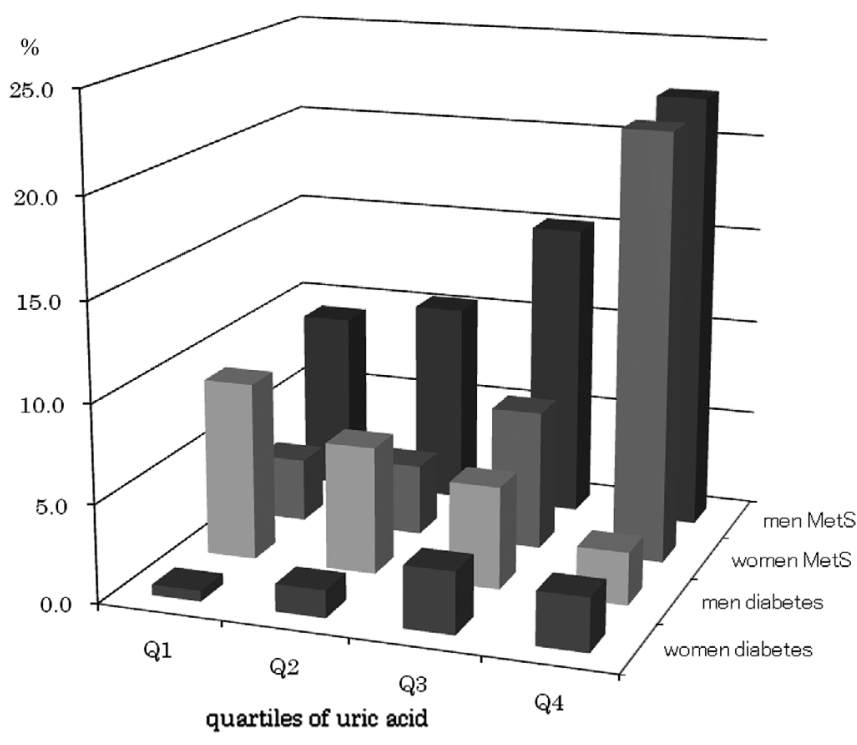

Figure 1. Prevalence of metabolic syndrome (MetS) and diabetes by quartiles of uric acid.

risk factors excluding diabetic patients. The correlation coefficient between uric acid and fasting glucose was 0.083 ( $\mathrm{p}<$ 0.0001 ) in men excluding diabetic individuals.

\section{Discussion}

The concept of insulin resistance syndrome (syndrome $\mathrm{X}$ ) (2) or MetS $(3,4)$ was considered as the clustering of risk factors for diabetes and cardiovascular disease in the same individual. However, in 2005, the American Diabetes Association and the European Association for the Study of Diabetes jointly stated that no existing definition of MetS meets criteria as a syndrome (5) and there have been endless debates on the pros and cons of diagnosing this syndrome for individuals (20-23). Criteria that regard obesity as an inevitable component of MetS have a serious pit hole because there are a substantial number of metabolically obese nor- mal weight individuals (24) and only about one-third of most insulin-resistant individuals are actually obese (22). An essential drawback of JMetS (visceral fat syndrome) (15) is that it regards subcutaneous adipose tissue as a protective factor against the morbid effect of visceral adipose tissue and ignores the risk contribution of abdominal subcutaneous adipose tissue (25-27). A detailed criticism was discussed in a recent review by Oda (28). JMetS or IDF MetS where obesity is an inevitable component is already revealed to be inferior to the revised NCEP MetS as a predictor of cardiovascular disease in Japanese $(18,19)$. Therefore, in the present study, NCEP criteria where obesity is not an inevitable component was adopted as the definition of MetS.

In the present cross-sectional study in Japanese, we found that 1) the prevalence of MetS increased linearly through the quartiles of serum uric acid level in both men and women, although the prevalence of diabetes was decreased linearly through the quartiles of uric acid in men, 2) the correlation between uric acid and age was negative in men, and 3) the correlation between uric acid and fasting glucose was not significant even after the adjustment for age in men. However, the correlation between uric acid and fasting glucose was weakly positive in men excluding diabetic patients.

Prospective studies of uric acid as an independent risk factor of diabetes are limited and controversial. Taniguchi et al investigated the association between serum uric acid level and incident diabetes in a prospective cohort study of 6,365 Japanese male employees aged 35-61 years and reported that uric acid was not significantly associated with incident diabetes (11). Nakanishi et al studied the association of serum uric acid with development of IFG or diabetes over a 6year follow-up among 2,310 Japanese male office workers aged 35-59 years and reported that the adjusted relative risk (95\% confidence interval) of quintile 2, 3, 4, and 5 of serum uric acid for IFG or diabetes was $1.55(0.95-2.63), 1.62$ (0.98-2.67), 1.61 (1.01-2.58), and 1.78 (1.11-2.85), respectively compared with quintile 1 of serum uric acid (12). 
Table 3. Spearman's Correlation Coefficients between Uric Acid and Other Related Risk Factors

\begin{tabular}{ccccc}
\hline & \multicolumn{2}{c}{ men } & \multicolumn{2}{c}{ women } \\
& & $\mathrm{n}=2449$ & $\mathrm{n}=1448$ & $\mathrm{p}$ \\
\hline age & $\mathrm{r}$ & $\mathrm{p}$ & $\mathrm{r}$ & $<0.0001$ \\
body mass index & -0.132 & $<0.0001$ & 0.167 & $<0.0001$ \\
body fat percentage & 0.242 & $<0.0001$ & 0.243 & $<0.0001$ \\
waist circumference & 0.181 & $<0.0001$ & 0.277 & $<0.0001$ \\
systolic blood pressure & 0.182 & $<0.0001$ & 0.146 & $<0.0001$ \\
diastolic blood pressure & 0.192 & $<0.0001$ & 0.200 & $<0.0001$ \\
fasting glucose & 0.038 & $<0.0001$ & 0.209 & $<0.0001$ \\
triglycerides & 0.255 & $<0.0001$ & 0.143 & $<0.0001$ \\
HDL cholesterol & -0.165 & $<0.0001$ & -0.124 & $<0.0001$ \\
high-sensitivity CRP & 0.199 & $<0.0001$ & 0.273 & $<0.0001$ \\
gamma glutamyltransferase & 0.264 & $<0.0001$ & 0.322 & $<0.0001$ \\
alanine aminotransferase & 0.239 & $<0.0001$ & 0.282 & $<0.0001$ \\
LDL cholesterol & 0.120 & $<0.0001$ & 0.137 & $<0.0001$ \\
hemoglobin A1c & -0.009 & $\mathrm{~ns}$ & 0.206 & $<0.0001$ \\
white blood cell count & 0.115 & $<0.0001$ & 0.164 & $<0.0001$ \\
eGFR* & -0.241 & $<0.0001$ & -0.333 & $<0.0001$ \\
\hline
\end{tabular}

*estimated glomerular filtration rate

Table 4. Age-adjusted Correlation Coefficients between Uric Acid and Other Related Risk Factors

\begin{tabular}{|c|c|c|c|c|}
\hline & \multicolumn{2}{|c|}{$\begin{array}{c}\text { men } \\
n=2446\end{array}$} & \multicolumn{2}{|c|}{$\begin{array}{l}\text { women } \\
n=1445\end{array}$} \\
\hline & $r$ & $p$ & r & $p$ \\
\hline body mass index & 0.230 & $<0.0001$ & 0.256 & $<0.0001$ \\
\hline body fat percentage & 0.014 & ns & 0.240 & $<0.0001$ \\
\hline waist circumference & 0.179 & $<0.0001$ & -0.002 & ns \\
\hline systolic blood pressure & 0.183 & $<0.0001$ & 0.170 & $<0.0001$ \\
\hline diastolic blood pressure & 0.205 & $<0.0001$ & 0.195 & $<0.0001$ \\
\hline fasting glucose & -0.023 & ns & 0.133 & $<0.0001$ \\
\hline triglycerides & 0.212 & $<0.0001$ & 0.261 & $<0.0001$ \\
\hline HDL cholesterol & -0.161 & $<0.0001$ & -0.115 & $<0.0001$ \\
\hline high-sensitivity CRP & 0.091 & $<0.0001$ & 0.172 & $<0.0001$ \\
\hline gamma glutamyltransferase & 0.185 & $<0.0001$ & 0.193 & $<0.0001$ \\
\hline alanine aminotransferase & 0.174 & $<0.0001$ & 0.224 & $<0.0001$ \\
\hline LDL cholesterol & 0.119 & $<0.0001$ & 0.104 & $<0.0001$ \\
\hline hemoglobin A1c & -0.046 & $<0.05$ & 0.154 & $<0.0001$ \\
\hline white blood cell count & 0.089 & $<0.0001$ & 0.197 & $<0.0001$ \\
\hline $\mathrm{eGFR}^{*}$ & -0.289 & $<0.0001$ & -0.318 & $<0.0001$ \\
\hline
\end{tabular}

*estimated glomerular filtration rate

However, the latter study combined IFG and diabetes together. This study design made it impossible to detect the direct association of uric acid with diabetes. Chien et al conducted a community-based prospective cohort study of a median 9-year follow-up among 2,690 Chinese subjects aged 35-97 years and reported that the adjusted relative risk ( $95 \%$ confidence interval) for diabetes in the fifth quintile of serum uric acid was $1.63(1.20-2.23)$ compared with the first quintile and, after additional adjustment for MetS, it was
1.40 (1.02-1.92) (13). However, after further adjustment for HOMA insulin resistance index, the association between uric acid and diabetes became non-significant (the relative risk of the fifth quintile compared with the first quintile became 1.22 [0.85-1.74]) (13). Chien et al combined men and women together. This method made it impossible to determine gender differences in the association between uric acid and diabetes. Nonetheless, these studies demonstrate that the association, if any, between uric acid and diabetes is medi- 
Table 5. Spearman's Correlation Coefficients between Uric Acid and Other Related Risk Factors Excluding Diabetic Patients

\begin{tabular}{|c|c|c|c|c|}
\hline & \multicolumn{2}{|c|}{$\begin{array}{c}\text { men } \\
n=2306\end{array}$} & \multicolumn{2}{|c|}{$\begin{array}{l}\text { women } \\
n=1420\end{array}$} \\
\hline & $r$ & $\mathrm{p}$ & $r$ & $p$ \\
\hline age & -0.124 & $<0.0001$ & 0.160 & $<0.0001$ \\
\hline body mass index & 0.257 & $<0.0001$ & 0.239 & $<0.0001$ \\
\hline body fat percentage & 0.188 & $<0.0001$ & 0.270 & $<0.0001$ \\
\hline waist circumference & 0.273 & $<0.0001$ & 0.153 & $<0.0001$ \\
\hline systolic blood pressure & 0.190 & $<0.0001$ & 0.193 & $<0.0001$ \\
\hline diastolic blood pressure & 0.196 & $<0.0001$ & 0.202 & $<0.0001$ \\
\hline fasting glucose & 0.083 & $<0.0001$ & 0.136 & $<0.0001$ \\
\hline triglycerides & 0.263 & $<0.0001$ & 0.237 & $<0.0001$ \\
\hline HDL cholesterol & -0.176 & $<0.0001$ & -0.121 & $<0.0001$ \\
\hline high-sensitivity CRP & 0.212 & $<0.0001$ & 0.271 & $<0.0001$ \\
\hline gamma glutamyltransferase & 0.274 & $<0.0001$ & 0.320 & $<0.0001$ \\
\hline alanine aminotransferase & 0.250 & $<0.0001$ & 0.275 & $<0.0001$ \\
\hline LDL cholesterol & 0.122 & $<0.0001$ & 0.144 & $<0.0001$ \\
\hline hemoglobin A1c & 0.037 & ns & 0.198 & $<0.0001$ \\
\hline white blood cell count & 0.129 & $<0.0001$ & 0.157 & $<0.0001$ \\
\hline $\mathrm{eGFR}^{*}$ & -0.227 & $<0.0001$ & -0.327 & $<0.0001$ \\
\hline
\end{tabular}

* estimated glomerular filtration rate

ated by insulin resistance. Chou et al reported in a study among 3,218 Chinese men and 4,265 Chinese women aged 30-89 years that the serum uric acid level was associated with insulin resistance and plasma glucose levels more strongly in women than in men (14). The correlation between serum uric acid and fasting glucose was negative in Austrian men (10) and was not significant in Japanese men in the present study. Serum uric acid has been described as being increased in the prediabetic stage of diabetes and as being decreased in overt diabetes (29). Conflicting data exist about uric acid levels in type 2 diabetes, as low levels were found in overt diabetes, while elevated serum uric acid is a feature of insulin resistance and impaired glucose tolerance (30). Bo et al reported that hyperuricemia in type 2 diabetes seems to be associated with MetS and the early onset or increased progression to overt nephropathy, while hypouricemia is associated with hyperfiltration and a late onset or decreased progression to overt nephropathy (30). In the present study, the prevalence of IFG was higher in Q4 than Q1 and the correlation between uric acid and fasting glucose was weakly positive in men, excluding diabetic patients. Thus, the negative association between serum uric acid levels and the prevalence of diabetes in Japanese men may be a result of hyperuricosuria in overt diabetes. However, this negative association between uric acid and diabetes was not seen in women.

\section{Limitations}

The present study is a cross-sectional study and the subjects were not a general population but rather visitors to a medical check-up center which is in a central city of a rural region in Japan and information about antihyperuricemic medication was not available. Studies with more detailed information among more general populations and other ethnic populations and prospective studies are required to confirm our conclusions.

\section{Acknowledgement}

The authors thank all subjects who participated in the study, the paramedical staff at our center who assisted the study, and Dr. Shinzo Tachikawa, Dr. Shinpei Yoshii, and Dr. Masaaki Okabe at Tachikawa Medical Center, and Professor Yoshifusa Aizawa at Niigata University Graduate School of Medical and Dental Sciences for their effort to construct the study environment. The authors received no grant and have no conflict of interest to declare.

\section{References}

1. Facchini F, Chen YD, Hollenbeck CB, Reaven GM. Relationship between resistance to insulin-mediated glucose uptake, urinary uric acid clearance, and plasma uric acid concentration. JAMA 266: 3008-3011, 1991.

2. Reaven GM. Role of insulin resistance in human disease. Diabetes 37: 1595-1607, 1988.

3. Alverti KGMM, Zimmet P, Shaw J. Metabolic syndrome-a new world-wide definition. A consensus statement from the International Diabetes Federation. Diabet Med 23: 469-480, 2006.

4. Grundy SM, Cleeman JI, Daniels SR, et al. Diagnosis and management of the metabolic syndrome: a statement for health care professionals: an American Heart Association/National Heart, Lung, and Blood Institute Scientific Statement. Circulation 112: 2735-2752, 2005. 
5. Kahn R, Buse J, Ferrannini E, Stern M. The metabolic syndrome: time for a critical appraisal: joint statement from the American Diabetes Association and the European Association for the Study of Diabetes. Diabetes Care 28: 2289-2304, 2005.

6. Koenig W, Meisinger C. Uric acid, type 2 diabetes, and cardiovascular diseases: Fueling the common soil hypothesis? Clin Chem 54: 231-233, 2008.

7. Patterson RA, Horsley ETM, Leake DS. Prooxidant and antioxidant properties of human serum ultrafiltrates toward LDL: important role of uric acid. J Lipid Res 44: 512-521, 2003.

8. Fang J, Alderman MH. Serum uric acid and cardiovascular mortality: The NHANES I epidemiologic follow-up study, 1971-1992. JAMA 283: 2404-2410, 2000.

9. Bos MJ, Koudstaal PJ, Hofman A, Witteman JCM, Breteler MMB. Uric acid is a risk factor for myocardial infarction and stroke. The Rotterdam Study. Stroke 37: 1503-1507, 2006.

10. Strasak A, Ruttmann E, Brant L, et al. Serum uric acid and risk of cardiovascular mortality: a prospective long-term study of 83,683 Austrian men. Clin Chem 54: 273-284, 2008.

11. Taniguchi Y, Hayashi T, Tsumura K, Endo G, Fujii S, Okada K. Serum uric acid and the risk for hypertension and type 2 diabetes in Japanese men: Osaka Health Survey. J Hypertens 19: 1209$1215,2001$.

12. Nakanishi N, Okamoto M, Yoshida H, Matsuo Y, Suzuki K, Tatara $\mathrm{K}$. Serum uric acid and risk for development of hypertension and impaired fasting glucose or type 2 diabetes in Japanese male office workers. Eur J Epidemiol 18: 523-530, 2003.

13. Chien K-L, Chen H-C, Chang W-T, Su T-C, Lee Y-T, Hu HB. Plasma uric acid and the risk of type 2 diabetes in a Chinese community. Clin Chem 54: 310-316, 2008.

14. Chou P, Lin KC, Lin HY, Tsai ST. Gender differences in the relationships of serum uric acid with fasting serum insulin and plasma glucose in patients without diabetes. J Rheumatol 28: 571-576, 2001.

15. The Examination Committee for Criteria of Metabolic Syndrome. Definition and criteria of metabolic syndrome. J Jpn Soc Intern Med 94: 794-809, 2005 (in Japanese).

16. Kadota A, Hozawa A, Okamura $\mathrm{T}$, et al. Relationship between metabolic risk factor clustering and cardiovascular mortality stratified by high blood glucose and obesity: NIPPON DATA90, 19902000. Diabetes Care 30: 1533-1538, 2007.

17. Saito I, Iso H, Kokubo Y, Inoue M, Tsugane S. Metabolic syn- drome and all-cause and cardiovascular disease mortality: Japan Public Health Center-based Prospective (JPHC) Study. Circ J 73: 878-884, 2009.

18. Kokubo $Y$, Okamura $T$, Yoshimasa $Y$, et al. Impact of metabolic syndrome components on the incidence of cardiovascular disease in a general urban Japanese population: the Suita study. Hypertens Res 31: 2027-2035, 2008.

19. Noda H, Iso H, Saito I, Konishi M, Inoue M, Tsugane S. The impact of the metabolic syndrome and its components on the incidence of ischemic heart disease and stroke: Japan Public Health Center-based Study. Hypertens Res 32: 289-298, 2009.

20. Grundy SM. Does the metabolic syndrome exist? Diabetes Care 29: 1689-1692, 2006.

21. Kahn R. The metabolic syndrome (emperor) wears no clothes. Diabetes Care 29: 1693-1696, 2006.

22. Reaven GM. The metabolic syndrome: is this diagnosis necessary? Am J Clin Nutr 83: 1237-1247, 2006.

23. Sattar N. Why metabolic syndrome criteria have not made prime time: a view from the clinic. Int J Obes 32 (S2): S30-S34, 2008.

24. Ruderman NB, Schneider SH, Berchtold $P$. The "metabolicallyobese," normal-weight individual. Am J Clin Nutr 34: 1617-1621, 1981.

25. Matsuzawa YM. Pathophysiology and molecular mechanism of visceral fat syndrome: the Japanese experience. Diabetes Metab Rev 13: 3-13, 1997.

26. Fox CS, Massaro JM, Hoffmann U, et al. Abdominal visceral and subcutaneous adipose tissue compartments. Association with metabolic risk factors in the Framingham Heart Study. Circulation 116: 39-48, 2007.

27. Pou KM, Massaro JM, Hoffmann U, et al. Visceral and subcutaneous adipose tissue volumes are cross-sectionally related to markers of inflammation and oxidative stress. The Framingham Heart Study. Circulation 116: 1234-1241, 2007.

28. Oda E. The metabolic syndrome as a concept of adipose tissue disease. Hypertens Res 31: 1285-1293, 2008.

29. Erdberg A, Boner G, van Dyk DJ, Carel R. Urine uric acid excretion in patients with insulin-dependent diabetes mellitus. Nephron 60: 134-137, 1992.

30. Bo S, Cavallo-Perin P, Gentile L, Repetti E, Pagano G. Hypouricemia and hyperuricemia in type 2 diabetes: two different phenotypes. Eur Clin Invest 31: 318-321, 2001.

(C) 2009 The Japanese Society of Internal Medicine http://www.naika.or.jp/imindex.html 